\title{
Nutritional status of children and adolescents in three Serbian enclaves in Kosovo and Metohija
}

Valentina Fabiano ${ }^{1}$, Lucia Barcellini ${ }^{1 *}$, Marco Ugo Andrea Sartorio ${ }^{1}$, Erica Pendezza', Alessandro Leone², Fabio Meneghin ${ }^{3}$, Dario Dilillo ${ }^{1}$ and Gian Vincenzo Zuccotti ${ }^{1}$

\begin{abstract}
Objective: To evaluate nutritional status of children and adolescents living in three Serbian enclaves in Kosovo and Metohija.

Methods: We conducted an observational cross-sectional, population-based study, enrolling children and adolescents who underwent a pediatric screening performed in the three Serbian enclaves of Gračanica, Gornje Kusce and Velika Hoča in Kosovo and Metohija. Children and adolescents (5-19years) of all ethnic groups were evaluated in one of the three free outpatient medical facilities in rural villages in Kosovo. Body weight and height were measured, height-for-age z- scores (HAZ) and BMl-for-age z-scores (BAZ) indicators were analyzed. The anthropometric indicators HAZ and BAZ distributions were compared between sex and ages using Fisher's exact test. A two-sample Z-test for proportions was used to detect differences in individual categories of height- and BMIfor-age categories across sexes and age classes.

Results: Three hundred twenty-eight children and adolescents (184 females, 56.1\% and 144 males, 43.9\%) aged between 5 and 19 years were enrolled in the study. 241/328 participants showed a normal linear growth; with significantly more girls (78.3\%) than boys (67.4\%) being in the normal category. Similarly, a significant difference in BAZ distribution between sexes was noted, with more females being in the normal BMI category compared to males (63.0\% vs 50.0\%, respectively). Underweight and severe underweight subjects showed a prevalence of 1.5 and $0.6 \%$, respectively. Overweight and obesity prevalence was 19.5 and $9.1 \%$, respectively, which was comparable to World Health Organization overweight and obesity prevalence data for Serbia.

Conclusions: Prevalence of undernutrition and severe undernutrition in children and adolescents living in three Serbian enclaves in Kosovo and Metohija is small. By contrast, a tendency to an increase in overweight and obesity, especially in the male population, was noted.
\end{abstract}

Keywords: Nutritional status, Children, Adolescents, Kosovo, Transitional countries

\footnotetext{
*Correspondence: lucia.barcellini@gmail.com

'Department of Pediatrics, Vittore Buzzi Children's Hospital, Università di Milano, 32, Via Castelvetro, 20154 Milan, Italy

Full list of author information is available at the end of the article
}

(c) The Author(s). 2021 Open Access This article is licensed under a Creative Commons Attribution 4.0 International License, which permits use, sharing, adaptation, distribution and reproduction in any medium or format, as long as you give appropriate credit to the original author(s) and the source, provide a link to the Creative Commons licence, and indicate if changes were made. The images or other third party material in this article are included in the article's Creative Commons licence, unless indicated otherwise in a credit line to the material. If material is not included in the article's Creative Commons licence and your intended use is not permitted by statutory regulation or exceeds the permitted use, you will need to obtain permission directly from the copyright holder. To view a copy of this licence, visit http://creativecommons.org/licenses/by/4.0/ The Creative Commons Public Domain Dedication waiver (http://creativecommons.org/publicdomain/zero/1.0/) applies to the data made available in this article, unless otherwise stated in a credit line to the data. 


\section{Backgrounds}

Improving the nutritional status in pediatric age is considered a key strategy for reaching global development goals and reducing the non-communicable diseases (NCDs) burden [1]. WHO's 2025 Global Targets for nutrition include, among others, a $40 \%$ reduction in the number of children under- 5 who are stunted, no increase in childhood overweight and reduction of wasting to below 5\% [2]. Even though several remarkable improvements in childhood nutrition have been achieved in the last decades, in low, middle-income and transitional countries undernutrition still remains a significant problem. Besides that, childhood overweight prevalence is seriously increasing [3].

Assessing the nutritional status of infants, children, and adolescents is key to enable the implementation of focused nutritional interventions, which might vary according to the specific regional and socio-political settings they are addressed to.

Recently published data about the nutritional status of infants and children from some developing or transitional countries is available, as in the case of subSaharan Africa or Asia [4-7]; however, data is very limited from other low-middle income countries such as Kosovo, one of the poorest countries in Europe.

In July 1999, UNICEF conducted a survey on Kosovar children aged between 0 and 5 years [8], reporting a $3.1 \%$ prevalence of acute malnutrition (weight for height $<-2 \mathrm{z}$-scores) and a $10.7 \%$ prevalence of chronic malnutrition (height for age $<-2$ z-scores). Two years later, in 2001, UNICEF [9], in collaboration with Kosovo's Institute for Public Health, found a 10\% prevalence of low height-for-age in children aged 6-59 months, and a $4 \%$ prevalence of low weight-for-height.

More recently, a single study has been published addressing the nutritional status of preschool children attending nursery schools in Kosovo [10]. Authors reported $3 \%$ of stunted and $1.9 \%$ of wasted children, whilst up to $8.9 \%$ of included children resulted to be overweight and $2.3 \%$ obese. $27.3 \%$ of children resulted to be at risk of becoming overweight. To our knowledge, no data about malnutrition and overweight in older children and adolescents living in Kosovo has been published to date.

The aim of the present study is to evaluate the nutritional status of a sample of children and adolescents from three Serbian enclaves in Kosovo and Metohija,

\section{DOCs for KiM}

DOCs for KiM (Doctors for Kosovo and Metohija) is a humanitarian project born from the collaboration between "Amici di Decani", a not-for-profit, apolitical, non-sectarian association involved in charitable activities and cultural promotion, and the Department of
Pediatrics of the Vittore Buzzi Children's Hospital, ASST-FBF-Sacco, University of Milan. The aim of the project was to establish medical facilities in order to offer free medical screenings to the pediatric population living in rural villages in Kosovo. The project has already set up three outpatient facilities in Serbian enclaves in Kosovo, in the rural villages of Gračanica, Gornje Kusce and Velika Hoča, fully equipped to perform pediatric screenings for about 3000 infants, children and adolescents living in those areas. A group of 12 pediatricians, 2 dietitians, 2 pediatric neurologists, and 1 ophthalmologist participated in the project between 2018 and 2019.

\section{Materials and methods}

This is a cross-sectional, population-based study involving children and adolescents who underwent a pediatric screening performed by the health personnel participating in the DOCs for KiM project. Two "health weeks" took place in November 2018 and October 2019, respectively, in the three Kosovarian villages of Gračanica, Gornje Kusce and Velika Hoča.

The opening of the three outpatient facilities offering free pediatric screenings was advertized through local broadcast, as well as through billboards in the streets a about 2 months before each of the two scheduled screening weeks. During the two "health weeks", the health personnel performed pediatric screenings in the outpatient facilities to all infants, children and adolescents of all ethnic groups who spontaneously sought medical advice. The pediatric screening included the collection of family history and personal medical history, an anthropometric assessment (height, weight, BMI), and a complete clinical examination of organs and systems. Children and adolescents aged between 5 and 19 years were eligible to participate in the present nutritional study.

The participation criteria included: (a) being a child or an adolescent evaluated in one of the three DOCs for KiM outpatient facilities during the "health week", (b) being aged between 5 and 19 years, and (c) parents/legal representatives expressing their consent to data collection and analysis. Anthropometric measurements were collected by the 2 trained dietitians following standard guidelines [11]. Body weight was measured with the subject in underwear or in light clothing, without shoes, and using the digital weight scale Seca 877. Measures were taken to the nearest $100 \mathrm{~g}$. The weighing scale was checked for accuracy with a standard weight every 50 measurements. Height was measured using the Seca 217 vertical stadiometer. The subject was in standing position with feet together, without shoes, and with shoulders, buttocks and heels touching the vertical measuring board. Measures were taken to the nearest $0,1 \mathrm{~cm}$, with the subject standing with the eyes in the Frankfort 
Table 1 World Health Organization 2007 reference cutoffs for screening of under- and over-nutrition

\begin{tabular}{ll}
\hline Parameter & $\begin{array}{l}\text { World Health Organization } \\
\text { 2007 reference }\end{array}$ \\
\hline Stunting (Height-for-age) & $<-2 \mathrm{SD}$ \\
Severe stunting (Height-for-age) & $<-3 \mathrm{SD}$ \\
Underweight (BMI-for-age) & $<-2 \mathrm{SD}$ \\
Severe Underweight (BMl-for-age) & $<-3 \mathrm{SD}$ \\
Overweight (BMI-for-age) & $>+1 \mathrm{SD}$ \\
Obesity (BMI-for-age) & $>+2 \mathrm{SD}$ \\
Severe Obesity (BMl-for-age) & $>+3 \mathrm{SD}$ \\
\hline
\end{tabular}

horizontal plane. Both the digital scale and the stadiometer were reliable and easy to use. The Body Mass Index (BMI) was calculated as weight $(\mathrm{kg}) /$ height $(\mathrm{m})^{2}$.

The results of weight and height measurements of children and adolescents in the three enclaves in Kosovo were compared with the growth charts from the World Health Organization (WHO Growth Reference 2007) and Z-scores were used for the comparisons. The anthropometric indicators height-for-age z-scores (HAZ) and BMI-for-age z-scores (BAZ) were used for all children and adolescents enrolled in the study [12]. The reference cutoffs for under- and over-weight screening are shown in Table 1.

The statistical analysis was performed using STATA version 12.0 (College Station, TX: StataCorp LP). Discrete variables are reported as frequency and percentage. HAZ and BAZ distributions between sexes and age classes were compared using Fisher's exact test. A twosample Z-test for proportions was used to detect differences in individual categories of height- and BMI-forage categories across sexes and age classes. A value of $p<0.05$ was considered statistically significant.

This study was conducted according to the guidelines set out in the Declaration of Helsinki and all procedures involving research study participants were approved by the Ethics Committee of ASST-FBF-Sacco. The DOCs for KiM humanitarian mission was positively welcomed by the population and all parents who turned up to the outpatient facilities to receive medical advice for their children accepted to participate in the data collection and in the study. Verbal informed consent was obtained from all parents/legal representatives of the included subjects and was witnessed and formally recorded in agreement with ASST-FBF-Sacco Ethic Committee's approval.

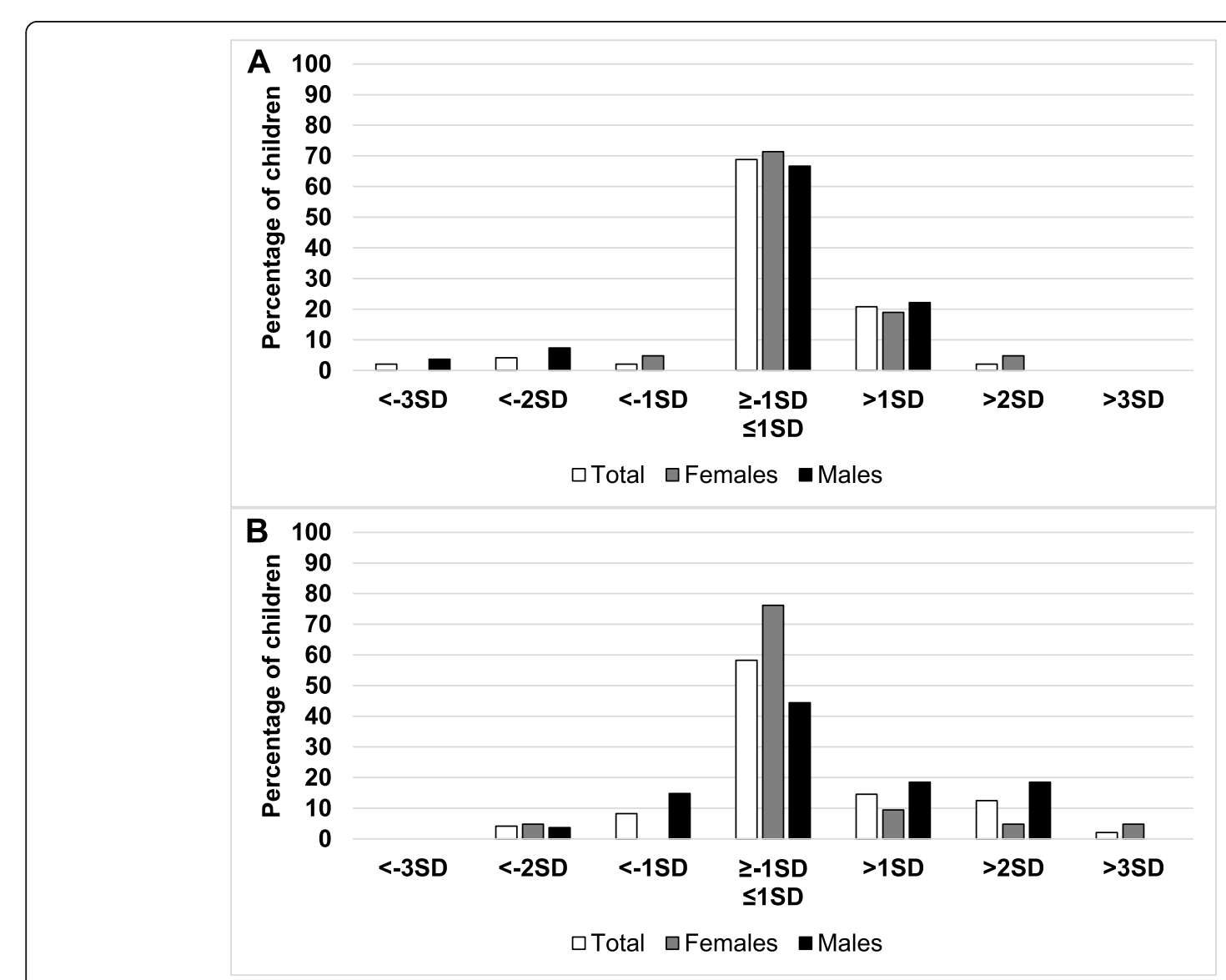

Fig. 1 Distribution of height-for-age (a) and BMI-for-age (b) categories by sex. ${ }^{*}=p<0.05$ among children (5-9years) 


\section{Results}

A total of 328 children and adolescents (184 females, $56.1 \%$ and 144 males, 43.9\%) aged between 5 and 19 years were enrolled in the study.

The overall distribution of HAZ categories by sex is reported in Fig. 1a (5-9 years) and Fig. 2a (10-19 years).

$241(73.5 \%)$ subjects (73.5\%) showed a HAZ between -1SD and +1SD, reflecting a largely normal linear growth. Sex-comparison in this HAZ category showed a statistically significant difference with more females being in the normal category compared to males $(78.3 \%$ vs $67.4 \%$, respectively). Stunting and severe stunting showed a prevalence of $1.2 \%$ and $0.3 \%$ respectively, without any difference between males and females.

The overall distribution of BAZ categories between sexes is reported in Fig. 1b (5-9 years) and Fig. 2b (1019 years). A statistically significant difference was found in the distribution of BAZ categories by sex $(p=0.040)$. One hundred eighty-eight subjects (57.3\%) showed a BAZ between -1SD and + 1SD. As for height indicators, a significant difference was noted in the BAZ distribution between sexes, with more females being in the normal BMI category compared to males $(63.0 \%$ vs $50.0 \%$, respectively). Underweight and severe underweight subjects showed a prevalence of $1.5 \%$ and $0.6 \%$ respectively, without any statistically significant difference between sexes. By contrast, the number of obese males (13.9\%) was higher than obese females (5.4\%) (BAZ $>+2 \mathrm{SD})$. The overweight and obesity prevalence in the sample was $19.5 \%$ and $9.1 \%$ respectively.

HAZ and BAZ distribution was also analyzed according to three age groups. A statistically significant difference was found in the distribution of HAZ and BAZ categories by age group $(p=0.001$ and $p=0.017$ respectively). Normal height ( $\leq-1 \mathrm{SD}$ to $\geq+1 \mathrm{SD})$ showed a different distribution across age groups, with $81.3 \%$ of adolescents (15-19ys) falling in this category compared to $68.8 \%$ of children aged $5-9$ years and $61 \%$ of teens aged 10-14 years, respectively. The same difference in distribution across age groups was observed with regards to BMI: normal BMI $(\leq-1 \mathrm{SD}$ to $\geq+1 \mathrm{SD})$ was more frequently observed in the adolescent group (15-19ys) as opposed to younger children and teens (5-9ys and 10$14 y$ ). Obesity (BAZ $>+2 \mathrm{SD})$ was also differently distributed across age classes; the percentage of obese children was higher among primary school children (12.5\%) and
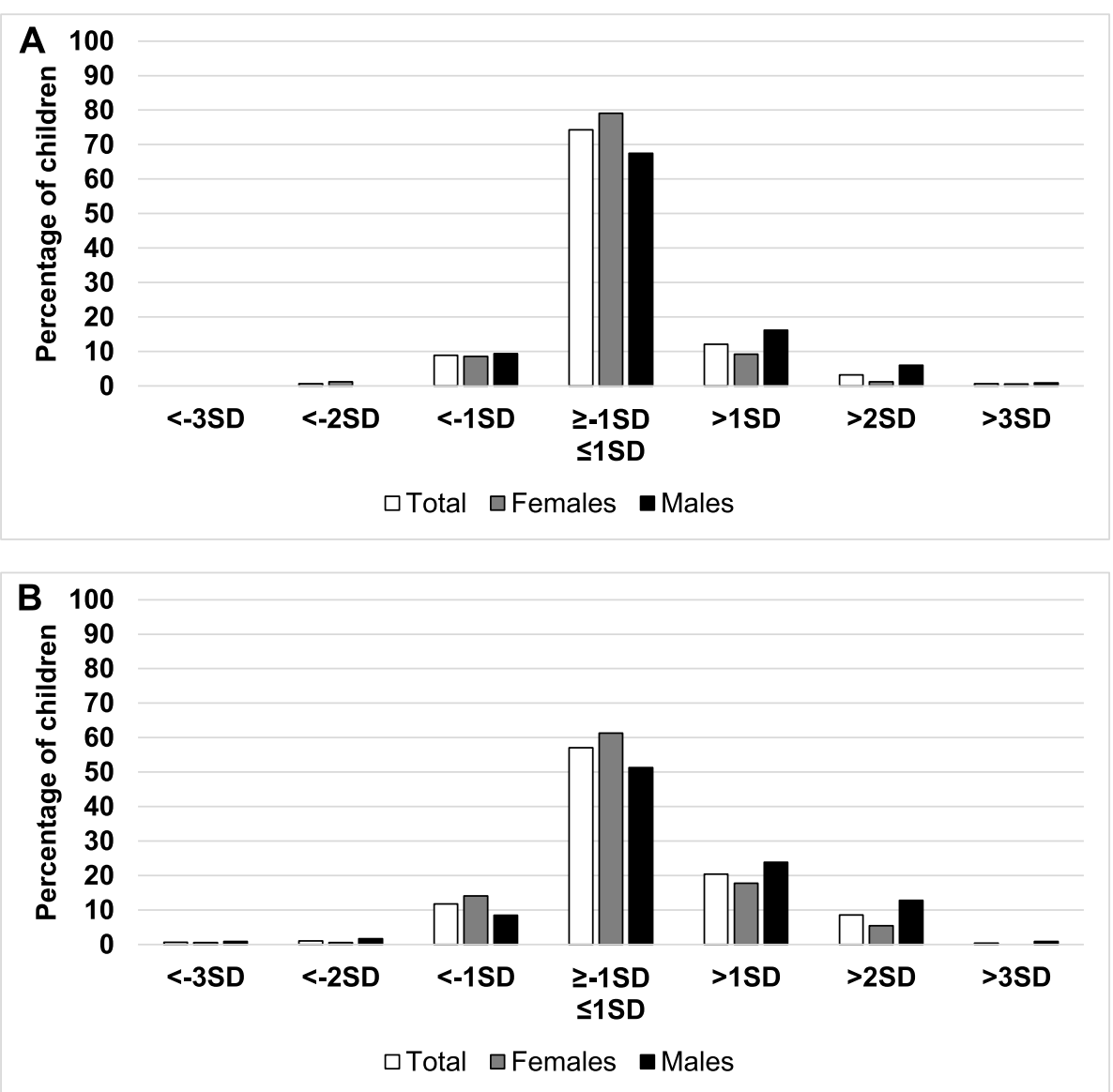

Fig. 2 Distribution of height-for-age (a) and BMI-for-age (b) categories by sex, $\left.{ }^{*}=p<0.05\right)$ among adolescent $(10-19$ years) 
children aged 10-14ys (14.3\%) compared to adolescents (5.5\%). Our data did not show any significant differences in overweight $(\mathrm{BAZ}>+1 \mathrm{SD})$ and severe obesity (BAZ > + 3SD) distribution across age groups (Table 2).

The distribution of height and BMI indicators across age classes were also evaluated separately in the male and female populations. The normal height indicator (HAZ between -1SD and + 1SD) was found more frequently in female adolescents compared to younger girls $(86.1 \%$ in $15-19 y$ ys vs. $71.4 \%$ in 5 -9ys and $62.5 \%$ in 10-14ys), which matches the results found across the whole population. However, a statistically significant difference was only found in the 15-19ys-group compared to the 10-14ys-group. By contrast, no differences in height indicators were observed across age classes in the male group. Normal BMI (BAZ between $-1 \mathrm{SD}$ and $+1 \mathrm{SD}$ ) also showed a different distribution across age classes in the female group only; however, the distribution did not reflect the results found across the whole population, since the highest percentage of normal BMI was observed in the 5-9 years age class (Table 3 A-B).

However, no conclusion should be drawn based on these observations given the limited number of subjects included in each group.

The distribution of HAZ across children and adolescents in our study was comparable to the WHO Growth reference (Fig. 3a-b-c).
The distribution of BAZ across the whole population and across females was comparable to the WHO Growth reference (Fig. 4a-b) as well.

In the male group, our subjects showed a higher tendency to overweight compared to the WHO Growth reference (Fig. 4c).

The total percentage of our subjects showing BAZ > + 2SD (9.1\%) was not significantly different from the WHO obesity prevalence data for Serbia $(9,8 \% ; p=0.97)$. The same result was also observed in relation to obesity prevalence by sex-category, which was lower in females than in males and matches the WHO obesity prevalence data for Serbia (F: $p=0.85$; M: $p=0.42$ ) [13].

\section{Discussion}

This study evaluated the nutritional status of children and adolescents from three Serbian enclaves in Kosovo through the collection of anthropometric measurements, performed during the two DOCs for KiM humanitarian missions.

Our data demonstrated that the prevalence of stunting and underweight (1.2 and 1.5\% respectively) across children and adolescents aged 5 to 19 years is generally low. This finding is in contrast with older UNICEF data $[8,9]$ which showed a $3.1 \%$ prevalence of acute malnutrition and a $10.7 \%$ prevalence of stunting across children aged 6-59 months. It is reasonable to assume that the Kosovar infants and children nutritional status, as described

Table 2 Anthropometric indicators by age

\begin{tabular}{|c|c|c|c|c|c|c|c|c|c|}
\hline & Total & & $5-9 y$ & & $10-1$ & & $15-19$ & & \\
\hline & $\mathrm{N}$ & $\%$ & $\mathrm{~N}$ & $\%$ & $\mathrm{~N}$ & $\%$ & $\mathrm{~N}$ & $\%$ & $p$ value \\
\hline Height-for-age & & & & & & & & & 0,001 \\
\hline$<-3 S D$ & 1 & 0.3 & $1_{a}$ & 2,1 & $\mathrm{O}_{\mathrm{a}}$ & 0 & $\mathrm{O}_{\mathrm{a}}$ & 0 & \\
\hline$<-2 S \mathrm{D}$ & 4 & 1.2 & $2 \mathrm{a}$ & 4,2 & $2_{a, b}$ & 2 & $O_{b}$ & 0 & \\
\hline$<-1 \mathrm{SD}$ & 26 & 7.9 & $1_{\mathrm{a}}$ & 2,1 & $11_{a}$ & 11,2 & $14_{a}$ & 7,7 & \\
\hline$>=-1 \mathrm{SD}<=1 \mathrm{SD}$ & 241 & 73.5 & $33_{a, b}$ & 68,8 & $60_{b}$ & 61,2 & $148 a$ & 81,3 & \\
\hline$>1 S D$ & 44 & 13.4 & $10_{a}$ & 20,8 & $18 \mathrm{a}$ & 18,4 & $16_{b}$ & 8,8 & \\
\hline$>2 \mathrm{SD}$ & 10 & 3.0 & $1_{a, b}$ & 2,1 & $\sigma_{b}$ & 6,1 & $3 a$ & 1,6 & \\
\hline$>3 S D$ & 2 & 0.6 & $0_{a}$ & 0 & $1_{\mathrm{a}}$ & 1 & $1_{\mathrm{a}}$ & 0,5 & \\
\hline Total & 328 & 100.0 & 48 & 100 & 98 & 100 & 182 & 100 & \\
\hline BMI-for-age & & & & & & & & & 0,017 \\
\hline$<-3 S D$ & 2 & 0.6 & $0_{a}$ & 0 & $1_{a}$ & 1 & $1_{a}$ & 0,5 & \\
\hline$<-2 S \mathrm{SD}$ & 5 & 1.5 & $2 \mathrm{a}$ & 4,2 & $2_{a, b}$ & 2 & $1_{b}$ & 0,5 & \\
\hline$<-1 S D$ & 37 & 11.3 & $4 a$ & 8,3 & $14_{a}$ & 14,3 & $19 a$ & 10,4 & \\
\hline$>=-1 \mathrm{SD}<=1 \mathrm{SD}$ & 188 & 57.3 & $28_{a, b}$ & 58,3 & $43 b$ & 43,9 & $117 a$ & 64,3 & \\
\hline$>1 S D$ & 64 & 19.5 & $7 a$ & 14,6 & $23 a$ & 23,5 & $34 a$ & 18,7 & \\
\hline$>2 S D$ & 30 & 9.1 & $\sigma_{a, b}$ & 12,5 & $14_{b}$ & 14,3 & $10_{a}$ & 5,5 & \\
\hline$>3 \mathrm{SD}$ & 2 & 0.6 & $1_{\mathrm{a}}$ & 2,1 & $1_{\mathrm{a}}$ & 1 & $\mathrm{O}_{\mathrm{a}}$ & 0 & \\
\hline Total & 328 & 100.0 & 48 & 100 & 98 & 100 & 182 & 100 & \\
\hline
\end{tabular}


Table 3 A-B Anthropometric indicators by age and sex (3A Female, 3B male)

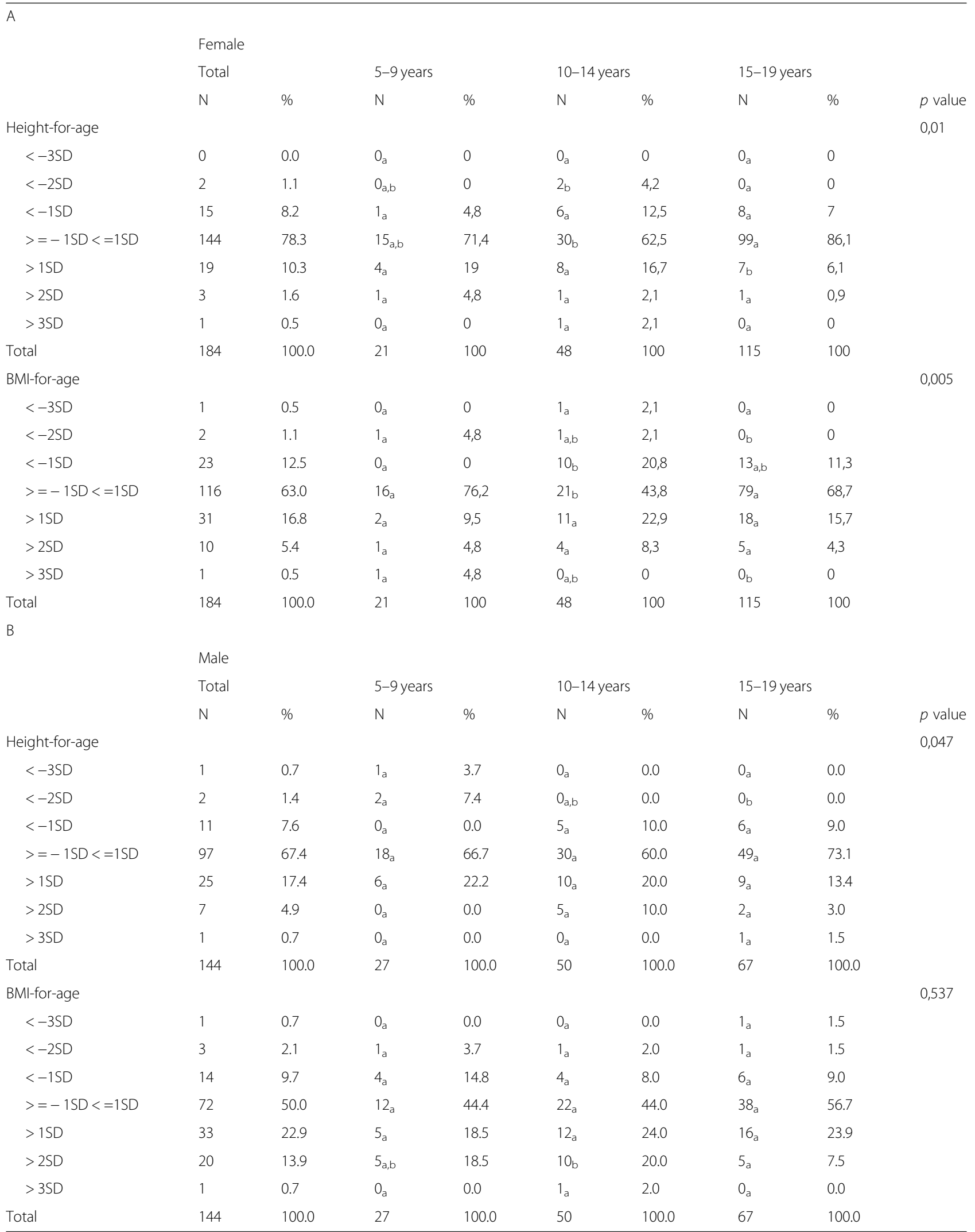

Different letters indicate statistically significant differences 


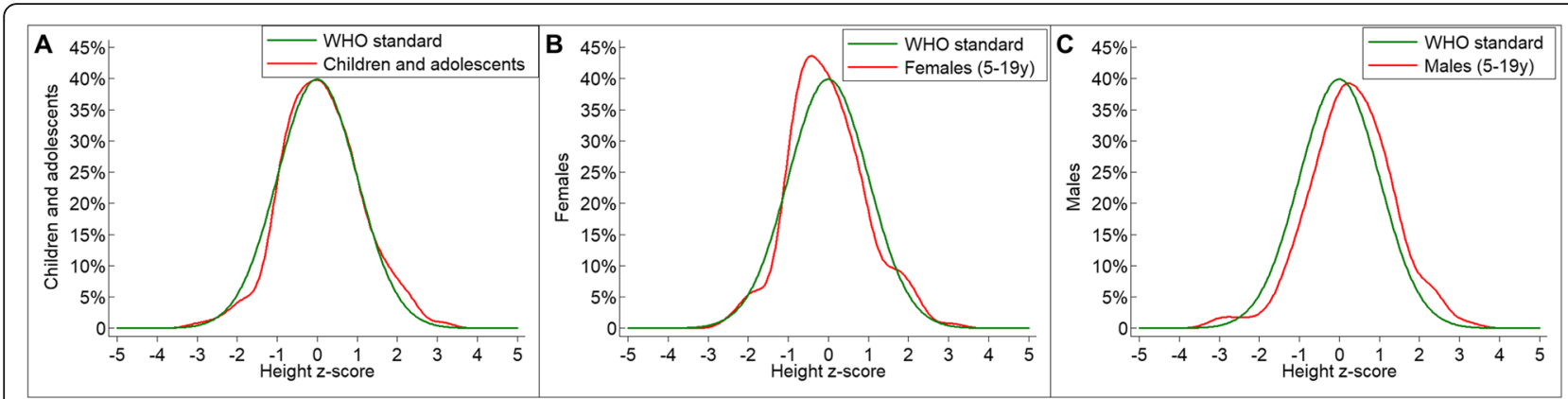

Fig. 3 Distribution of HAZ compared to WHO Growth reference in $\mathbf{a}$ all children and adolescents, $\mathbf{b}$ females (5-19 years) and $\mathbf{c}$ males (5-19 years)

by UNICEF, might have been poorer since the UNICEF data was collected 20 years ago, at the time of the Kosovo War coming to its end. By contrast, 1,2\% stunting and 1,5\% underweight subjects were found in our study, which suggests that malnutrition might be less prevalent nowadays. The undernutrition prevalence in our study was also lower than the $3 \%$ prevalence of stunting from a study performed in Kosovo in 2017 [10]. Although Kosovo remains one of the poorest countries in Europe, it has undergone a slow though progressive transition to better living conditions. The anthropometric data of the present study might suggest an improvement in the nutritional status in pediatric age compared to previously published data. However, we cannot exclude that our observations might be based on an underestimate, given the reduced sample size. Moreover, in drawing comparisons, it is important to consider that both the UNICEF data $[8,9]$ and those by Rysha et al. were collected in infants and children aged under 5 , whilst the data from the present study concerned older children and adolescents. Nevertheless, a better nutritional status in older children and adolescents might be considered as a consequence of a better nutritional status since infancy and early childhood. In fact, we should also consider that the anthropometric measurements of the present study were collected in a sample of subjects who spontaneously turned up to the outpatient facilities, therefore, our observations might be the result of a selection bias, since the families who decided to participate in the data collection might have been the ones with a better awareness of the importance of prevention and medical screening.

In our population, a different distribution of normal height and weight was observed based on age. In both instances, the percentages of normal height (HAZ between -1SD and + 1SD) and of normal BMI (BAZ between -1SD and + 1SD) were higher in the adolescent group than across younger teens and children. Despite this observation, we did not find any statistically significant difference in the distribution of pathologic BMI classes, although we observed a rather clear tendency to overweight across the younger children compared to older children, teens and adolescents. The lack of statistical significance might be explained based on the small sample size of each age group.

Obesity and overweight had a $9,1 \%$ and $19,5 \%$ prevalence, respectively. The obesity prevalence in our study was higher compared to the previous data collected in younger children in Kosovo in 2017 [10], which showed an obesity prevalence of 2,3\%. The prevalence of overweight was also found to be higher compared to Rysha et al. [10], who, however, operated a distinction between overweight $(8,9 \%)$ and risk of being overweight $(27,3 \%)$, by also referring to the $2006 \mathrm{WHO}$ standards for infants and younger children. Our overweight and obesity
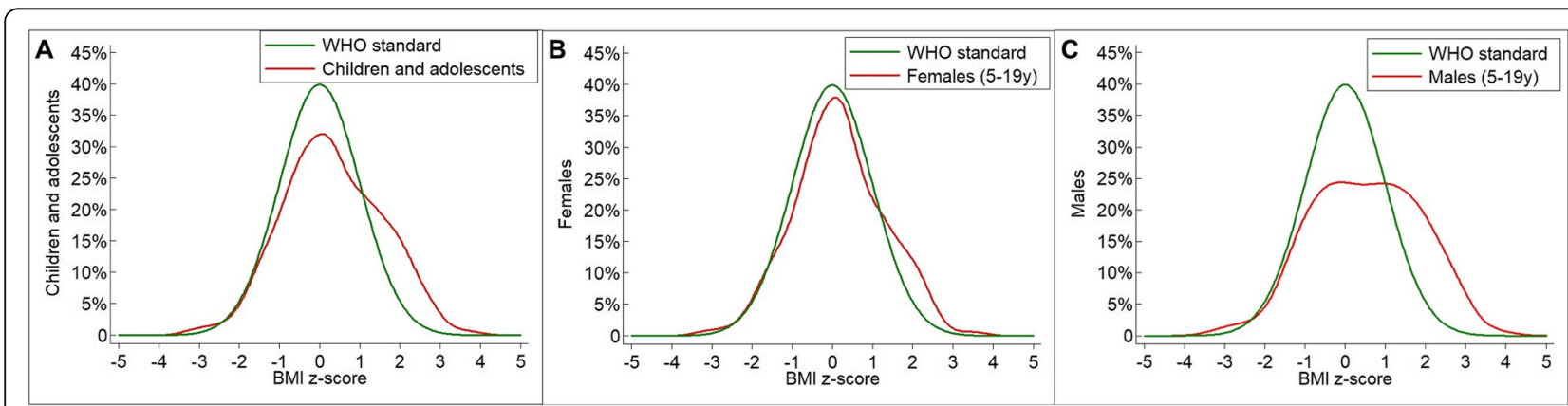

Fig. 4 Distribution of BAZ compared to WHO Growth reference in a all children and adolescents, $\mathbf{b}$ females (5-19 years) and $\mathbf{c}$ males (5-19 years) 
prevalence data is in line with the overweight [14] and obesity [13] WHO prevalence data for the Serbian population aged $5-19$ years.

When considering the BMI distributions according to age and sex group, normal weight was found to be significantly more common in females than in males. In fact, the BAZ distribution curve of our male patients is significantly more flat than the WHO reference curve, which reflects the lower percentage of male being in the normal BAZ category, and, though not statistically significant, a tendency to overweight and obesity.

This study shows some limitations. Firstly, the small sample size, since the 328 enrolled subjects represent only $10 \%$ of the nearly 3000 infants, children and adolescents estimated to be living in those three enclaves. This limitation is even more evident in conducting analyses across different age groups. Another limitation is the cross-sectional study design. The subjects included in the study spontaneously turned up to the outpatient facilities, thus potentially determining a selection bias. Moreover, we exclusively collected weight and height data. It would be meaningful to evaluate other anthropometric indexes, such as body circumferences and skinfold thickness measurements. Lastly, the subjects included in the study were mainly Serbian, however, no specific data on ethnic origin was collected and therefore we were unable to draw a comparison across children and adolescents of different ethnicities.

As a future perspective, it would be interesting to compare the present data with data collected in a further nutritional study conducted on the same population.

\section{Conclusions}

Our data demonstrated that the undernutrition $(1.5 \%)$ and severe undernutrition $(0.6 \%)$ prevalence in children and adolescents living in three Serbian enclaves in Kosovo and Metohija is marginal and has presumably declined over the last two decades. This is a reassuring result given that, although the country's hardest time is over, Kosovo is still one of the poorest countries in Europe and the living conditions of infants, children and adolescents, and especially of those belonging to ethnic minorities, are still far below European standards.

By contrast, the tendency to an increase in overweight and obesity represents a worrying trend. Overweight children would benefit from receiving support since early infancy in relation to healthy weight maintenance, physical activity opportunities, and chronic disease prevention. Interventions should address the whole spectrum of malnutrition, taking into account overweight prevention as well as undernutrition.

Even though some positive trend is shown by the results of the present study, evaluating the nutritional status of infants, children and adolescents remains key, and should be addressed as a matter of priority by health policies in less developed countries. Our study is the first in this field taking into account the nutritional status in the Serbian-Kosovar pediatric population over 5 years, and provides up-to-date data collected in one of the most neglected European regions.

\section{Abbreviations \\ HAZ: height-for-age z- scores; BMI: body mass index; BAZ: BMI-for-age z- scores; WHO: World Health Organization}

\section{Acknowledgements \\ We would like to thank all doctors and dieticians who participated in the two missions. \\ DOCs for KiM 2018: Alessandra Bosetti, Stefania Del Sesto, Giulia Franchino, Laura Paradiso, Sara Olivotto, Marco Sala, Ivanka Zdravković Dardi. \\ DOCs for KiM 2019: Stefania Bova, Giorgio Martini, Arianna Sangiorgio, Giulia Zichichi. \\ A very special thank to Alessandro Visconti, Daniela Ghioni, Pietro Favaro, Uomo Libero Onlus, to the Giorgioni, Zradvković and Semeraro families and to the Amici di Dečani NGO.}

\section{Authors' contributions}

Valentina Fabiano: conceptualized the study, collected data, drafted the manuscript and gave final approval. Lucia Barcellini: collected data, drafted the manuscript and gave final approval. Marco Ugo Andrea Sartorio: collected data, drafted the manuscript and gave final approval. Erica Pendezza: collected data, drafted the manuscript and gave final approval. Alessandro Leone: analyzed data, drafted the manuscript and gave final approval. Fabio Meneghin: collected data, drafted the manuscript and gave final approval. Dario Dilillo: conceptualized the study, collected data, supervised the team work and gave final approval. Gian Vincenzo Zuccotti: conceptualized the study, supervised the team work and gave final approval.

\section{Funding}

This research received no specific grant from any funding agencies, commercial or not-for-profit sectors.

Availability of data and materials

The datasets used and/or analyzed in the current study are available from the corresponding author upon reasonable request.

\section{Declarations}

\section{Ethics approval and consent to participate}

The study was conducted according to the guidelines set out in the Declaration of Helsinki and all procedures involving research study participants were approved by the Ethics Committee of ASST-FBF-Sacco. Verbal informed consent was obtained from all parents/legal representatives of the included subjects and was witnessed and formally recorded.

\section{Consent for publication}

Not applicable.

\section{Competing interests}

The authors have no conflict of interest to declare.

\section{Author details}

${ }^{1}$ Department of Pediatrics, Vittore Buzzi Children's Hospital, Università di Milano, 32, Via Castelvetro, 20154 Milan, Italy. ${ }^{2}$ International Center for the Assessment of Nutritional Status (ICANS), Department of Food, Environmental and Nutritional Sciences (DeFENS), Università di Milano, Milan, Italy. ${ }^{3}$ Neonatal Intensive Care Unit, Vittore Buzzi Children's Hospital, Università di Milano, Milan, Italy. 
Received: 14 January 2021 Accepted: 13 April 2021

Published online: 24 April 2021

\section{References}

1. Williams AM, Suchdev PS. Assessing and improving childhood nutrition and growth globally. Pediatr Clin N Am. 2017;64(4):755-68. https://doi.org/10.101 6/j.pcl.2017.03.001.

2. WHO. Global Targets 2025 - To improve maternal, infant and young children nutrition. https://www.who.int/nutrition/global-target-2025/en/. Accessed 30 Mar 2020.

3. Abdullah $\mathrm{A}$. The double burden of undernutrition and overnutrtion in developing countries: an update. Curr Obes Rep. 2015;4(3):337-49. https://doi.org/10.1007/s13679-015-0170-y.

4. Hoffman D, Cacciola T, Barrios P, Simon J. Temporal changes and determinants of childhood nutritional status in Kenya and Zambia. J Health Pop Nutr. 2017;36(1):27. https://doi.org/10.1186/s41043-017-0095-z.

5. Dabonè $\mathrm{C}$, Delisle $\mathrm{HF}$, Receveur $\mathrm{O}$. Poor nutritional status of schoolchildren in urban and peri-urban areas of Ouagadougou (Burkina Faso). Nutr J. 2011; 10(1):34. https://doi.org/10.1186/1475-2891-10-34.

6. Mushtaq MU, Gull S, Mushtaq K, Abdullah HM, Khurshid U, Shahid U, et al. Height, weight and BMl percentiles and nutritional status relative to the international growth references among Pakistani school-aged children. BMC Pediatr. 2012;12(1):31. https://doi.org/10.1186/1471-2431-12-31.

7. Wickramasinghe VP, Lamabadusuriya SP, Atapattu N, Sathyadas G, Kuruparanantha S, Karunarathne P. Nutritional status of schoolchildren in an urban area of Sri Lanka. Ceylon Med J. 2004;49(4):114-8. https://doi.org/10.4 038/cmj.v49i4.1920.

8. UNICEF. Action against hunger. Pristina: Nutritional Anthropometric and Infant Feeding and Weaning Survey; 1999.

9. UNICEF. Micronutrient Status Survey-Kosovo. 2001. p. 1-2. https://www. unicef.org/kosovoprogramme/kosovo_media_pub_survival.004.04.pdf. Accessed 30 Mar 2020.

10. Rysha A, Gjergji TM, Ploeger A. Nutritional status of preschool children attending kindergartens in Kosovo. J Health Pop Nutr. 2017;36(1):26. https://doi.org/10.1186/s41043-017-0105-1.

11. Lohman TG, Roche AF, Martorell R. Anthropometric standardization reference manual. Champaign: Human Kinetics Books; 1988.

12. WHO. Growth Reference Data for 5-19 years. https://www.who.int/toolkits/ growth-reference-data-for-5to19-years. Accessed 1 Nov 2020.

13. $\mathrm{WHO}$. Prevalence of obesity among children and adolescents, BMI $>+2$ standard deviations above the median (crude estimate) (\%). https://www. who.int/data/gho/data/indicators/indicator-details/GHO/prevalence-ofobesity-among-children-and-adolescents-bmi-2-standard-deviations-abovethe-median-(crude-estimate)-(-). Accessed 1 Nov 2020.

14. WHO. Prevalence of overweight among children and adolescents, $\mathrm{BMI}>+1$ standard deviations above the median (crude estimate) (\%). https://www. who.int/data/gho/data/indicators/indicator-details/GHO/prevalence-ofoverweight-among-children-and-adolescents-bmi-1-standard-deviations-a bove-the-median-(crude-estimate)-(-). Accessed 1 Nov 2020.

\section{Publisher's Note}

Springer Nature remains neutral with regard to jurisdictional claims in published maps and institutional affiliations. 